
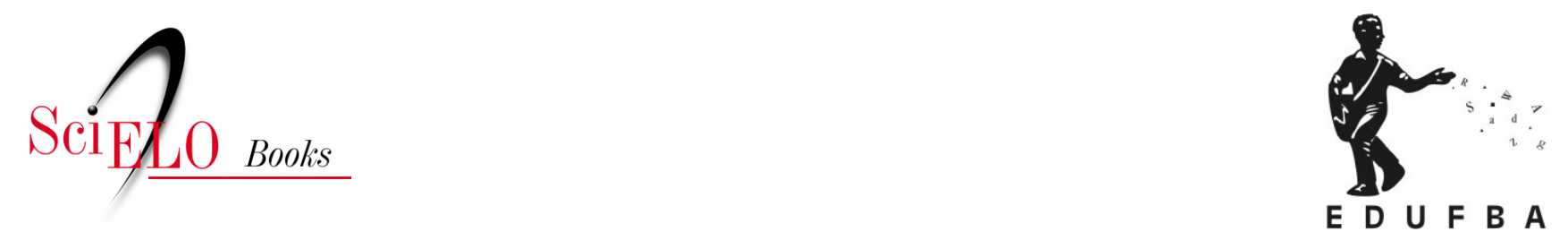

\title{
Configuração política e relações de poder
}

\author{
Danila Gentil Rodriguez Cal
}

\section{SciELO Books / SciELO Livros / SciELO Libros}

CAL, D.G.R. Configuração política e relações de poder. In: Comunicação e trabalho infantil doméstico: política, poder, resistências [online]. Salvador: EDUFBA, 2016, pp. 75-103. ISBN: 97885-232-1870-6. https://doi.org/10.7476/9788523218706.0006.

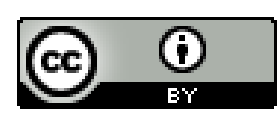

All the contents of this work, except where otherwise noted, is licensed under a Creative Commons Attribution $\underline{4.0 \text { International license. }}$

Todo o conteúdo deste trabalho, exceto quando houver ressalva, é publicado sob a licença $\underline{\text { Creative Commons }}$ Atribição 4.0.

Todo el contenido de esta obra, excepto donde se indique lo contrario, está bajo licencia de la licencia $\underline{\text { Creative }}$ Commons Reconocimento 4.0. 


\section{Configuração política e relações de poder}

- Então, o meu sonho é me formar em direito, mas na defesa do trabalhador doméstico. Hoje, eu tenho um filho de estupro, de patrão, não é? Meu filho mais velho e eu amo meu filho, meu filho não tem culpa do que aconteceu, até porque ele [o ex-patrão] pediu que eu abortasse a criança. E eu sempre tive uma consciência que na vida você tem que passar por muita coisa, entendeu? E, hoje, o meu filho é tudo que eu tenho, é uma coisa maravilhosa, ele trabalha com dedetização e tudo que ele fazé em prol da mãe dele.

Zezé, participante do Grupo focal "Sindicato I".

Tomamos por hipótese a existência de um jogo complexo de relações de poder em torno do TID, as quais não se configuram apenas como dominação e reprodução de estigma e subalternidade - tal como largamente abordado na literatura sobre o assunto. (BLAGBROUGH, 2008; LAMARÃO, 2008; LAMARÃO; MACIEL, 2006) A nosso ver, essa complexidade repercute na configuração do TID como 
questão política, tanto no modo através do qual o assunto é tematizado publicamente nos media, quanto na forma pela qual meninas e mulheres constroem e articulam sentidos discursivamente sobre ele.

Neste capítulo, abordaremos inicialmente o conceito de político com o qual trabalhamos. O que significa dizer que um problema é uma questão política? Recorremos, nesse intento, a três autores principais: Jürgen Habermas, Jane Mansbridge e Axel Honneth. Embora tenham perspectivas relativamente distintas, as abordagens desses autores contribuirão para lançarmos luz sobre elementos importantes da politização do TID. Em seguida, discutiremos a relação entre poder e desigualdade. Autores como Jessé de Souza (2009) e Patrícia Mattos (2006) afirmam que a naturalização das desigualdades no Brasil é fruto da atuação de consensos inarticulados que orientam tacitamente os lugares e os papéis de cada um e que colocam os sujeitos da classe a qual eles chamam de "ralé" em situação de subordinação e de aceitação dessas assimetrias.

Poder, nessa perspectiva, é entendido como uma relação de dominação latente que ocorre a partir da internalização de constrangimentos e pressupostos sobre o que cabe ao dominador e ao dominado. No entanto, essa é somente uma das visadas sobre poder. E, como mencionado em nosso primeiro capítulo, essa é a perspectiva mais usual na literatura a respeito do TID. Para realizar esta pesquisa, consideramos necessário buscar outras acepções ou, ao menos, novos matizes para o entendimento mais complexo das relações de poder que, ao mesmo tempo, atravessam e sustentam o TID.

Desse modo, recorremos, sobretudo, a Amy Allen, que, frente a diversos usos e sentidos de poder nas teorias feministas, organizou o debate a partir de três concepções: power over, power to e power with. No cerne desses entendimentos sobre poder, estão os conceitos de dominação, resistência, empoderamento e solidariedade que, conforme sustentaremos ao longo desta pesquisa, têm relação com os modos de compreensão do TID entre um assunto privado ou um tema político que suscita preocupação pública. 


\section{PRÉ-POLÍTICO OU POLÍTICO}

O que faz com que um problema seja reconhecido como questão política?

Parte da literatura sobre o assunto procura fazer distinção entre o que seria do âmbito do privado e o que seria do âmbito público, considerado, por vezes, o lócus da política. (ARENDT, 1991) A respeito do posicionamento na teoria política acerca dessa relação, Okin (2008) analisa a configuração histórica da dicotomia entre público e privado. Segundo a autora, há duas ambiguidades principais envolvidas nos usos desses conceitos e iluminadas a partir dos estudos feministas: (1) público/privado como Estado/sociedade ou ainda vida não-doméstica/vida doméstica; (2) público/privado como, respectivamente, masculino/feminino.

De acordo com o primeiro tipo de entendimento, bastante recorrente na teoria política, o Estado "é (paradigmaticamente) público e a família e a vida íntima e doméstica são (também paradigmaticamente) privadas”. (OKIN, 2008, p. 307) Entretanto, a sociedade civil, ora pode ser considerada âmbito privado (como contraponto ao Estado), ora âmbito público (como contraponto à vida doméstica). Okin (2008) afirma que a dicotomia público/doméstico alimenta perspectivas que não consideram a "natureza política da família" e "a relevância da justiça na vida pessoal". Nesse sentido, o TID seria, a rigor, um tema do âmbito privado, pois se concretiza no ambiente íntimo das casas de família e tende a ser considerado algo que diz respeito apenas aos membros daquele núcleo familiar. Mesmo que haja problematização dessa questão por organizações da sociedade civil, ainda assim, ela pode ser considerada, segundo essa perspectiva, uma interferência "pública" na vida doméstica.

A segunda ambiguidade discutida por Okin (2008) é baseada na divisão sexual do trabalho, segundo a qual, às mulheres, caberia a responsabilidade pelo espaço doméstico e pela reprodução e, aos homens, as atividades econômicas e políticas. De acordo com Okin, "As mulheres têm sido vistas como 'naturalmente' inadequadas à esfera pública, dependentes dos homens e subordinadas à família”. (OKIN, 2008, p. 308) Nessa perspectiva, a defesa irrestrita da privacidade em relação à publicizição e à politização pode significar a proteção contra interferências (do Estado, da Igreja, da sociedade) em relações de controle e subordinação exercidas pelos adultos chefes de família no ambiente doméstico contra "aqueles que, seja pela idade, sexo ou condição de servidão, eram vistos como legitimamente controlado por eles tendo sua existência limitada à sua esfera de 
privacidade”. (OKIN, 2008, p. 308, grifo nosso) Esse viés confina crianças e adolescentes envolvidos no TID ao espaço da família, como se não lhes coubesse ter voz ativa na vida pública.

Baseados em Arendt (1991 ou 1994), argumentamos em outro momento (CAL, 2007) que o lar seria o espaço das relações íntimas que ocorreriam livres do constrangimento da visibilidade social. "É como se os fatos que acontecem nos lares dissessem respeito apenas aos que dele participam e não aos outros, portanto, é como se 'não existissem' publicamente”. (CAL, 2007, p. 15) O lar, então, seria o lugar do pré-político, e a ágora, o palco político por excelência no qual os assuntos públicos seriam decididos pelos cidadãos. (ARENDT, 1991)

Em contraposição a essa visada sobre o tema, Mansbridge $(1999,2009)$ retoma a ideia cunhada por Carol Hainisch de que o "pessoal é político". A autora defende que a configuração de uma questão como política não está circunscrita ao que ocorre em público, mas diz respeito "àquilo sobre o qual o público deve discutir", ainda que sejam temas aparentemente bastante pessoais e privados, como orgasmo ou menstruação. (MANSBRIDGE, 2009, p. 212) A proposta da autora é que haja um alargamento do conceito de político para que não abarque apenas o que ocorre e o que é discutido na cena pública. Por essa razão, Mansbridge objetiva valorizar o lugar das conversações e das disputas políticas cotidianas em relação a um processo mais amplo de formação de opinião e de vontade políticas.

A esse respeito, Okin (2008) esclarece que a expressão "o pessoal é político" é objeto de tensão e discussão entre teóricas feministas. Para além de uma interpretação literal, que remeteria à ideia de união entre as duas esferas (pública/privada), a autora afirma que manter a ideia de privacidade é importante, mesmo porque algumas demandas feministas (como as ligadas aos direitos reprodutivos) são baseadas em modos distintos de privacidade. No entanto, segundo Okin (2008), é preciso haver um terreno mínimo de igualdade no âmbito doméstico para ela, que seja consistente com a "privacidade e a segurança socioeconômica de mulheres e crianças”. (OKIN, 2008, p. 314)

Permanece, contudo, a questão: como podemos entender a expressão "o pessoal é político”? Okin oferece uma possibilidade de resposta:

Nós queremos dizer, primeiramente, que o que acontece na vida pessoal, particularmente nas relações entre os sexos, não é imune em 
relação à dinâmica de poder, que tem tipicamente sido vista como a face distintiva do político. E nós também queremos dizer que nem o domínio da vida doméstica, pessoal, nem aquele da vida não-doméstica, econômica e política, podem ser interpretados isolados um do outro. (OKIN, 2008, p. 314)

Para essa autora, não se trata de uma sobreposição dos reinos privado e público, mas, sobretudo, de estimular um olhar crítico para relações íntimas, que ocorrem na vida doméstica e que também são perpassadas por dinâmicas de poder. Segundo Mendonça (2012), essa politização do espaço doméstico demonstrou a impossibilidade de fixar fronteiras rígidas entre o que seria público ou privado.

Para Mansbrigde (1999, 2009), a expressão “o pessoal é político” significa que determinados temas relacionados ao cotidiano e à intimidade podem se tornar questões políticas, sendo definidas como aquilo que merece ser discutido por um público. Esse processo que caracteriza o "político" precisa estar relacionado a algum tipo de decisão coletiva com vistas a mudanças. A tese sustentada pela autora é a de que essa tomada de decisão não passaria apenas pelo aparato do Estado, e sim abrangeria os cidadãos privados que, enquanto coletividade, realizam escolhas constantemente. Processos informais como as conversações cotidianas, portanto, teriam forte apelo político por conta das repercussões que geram no dia a dia dos sujeitos.

Mansbridge $(1999,2009)$ recorre a Beiner, para quem "político" se refere ao modo pelo qual os sujeitos buscam "fazer sentido de sua situação comum através do discurso intersubjetivo”. (BEINER, 1983 apud MANSBRIDGE, 2009, p. 215) Assim, há um comum compartilhado, sobre o qual se faz sentido também de modo partilhado e, para Mansbridge, a produção de sentidos constitui uma dimensão importante da ação política em termos amplos, ainda que a ação possa significar a decisão de não agir.

Essa conceituação está próxima a de Held (1987), para quem política é uma dimensão universal da vida humana e diz respeito à capacidade que as pessoas têm de julgar, deliberar e decidir agir ou não para transformar o contexto no qual vivem. Desse modo, segundo Held (1987), a política está no centro do desenvolvimento dos problemas da sociedade e dos modos coletivos de resolução: 
O político trata do poder; ou seja, trata da capacidade dos agentes, órgãos e instituições sociais de manter ou transformar seu ambiente, social ou físico. Ele trata de recursos subjacentes à sua capacidade e das forças que moldam o seu exercício [...]. Consequentemente a política é encontrada em e entre todos os grupos, instituições (formais e informais) e sociedades, perpassando a vida pública e privada. Ela está expressa em todas as atividades de cooperação, negociação e luta pela distribuição de recursos. (HELD, 1987, p. 250, grifo do autor)

Held (1987) desenvolve essa concepção alargada de política como base para a construção de um modelo democrático baseado no princípio da autonomia dos sujeitos. Apesar de concordarmos com boa parte das proposições do autor, a referência à ideia de política como "cooperação, negociação e luta pela distribuição de recursos” acaba por restringir a dimensão discursiva da política, tal como criticado por Mansbridge (1999, 2009).

Em relaçãoà proposta de Mansbridge (1999, 2009), percebemos em Habermas (2003) uma sutil, porém decisiva, diferença no que concerne à conceituação de política. Enquanto que, para a primeira, político é todo o tema sobre o qual um público precisa decidir, para Habermas, um assunto é político quando se torna reconhecido como tal por meio de processos de debate público. (HABERMAS, 2003) Assim, segundo o autor, diversos temas teriam possibilidade de fomentar a discussão na esfera pública, no entanto, somente na medida em que adquirissem o status de questão de interesse geral. (HABERMAS, 2003; MAIA, R., 2008b)

Acerca da relação entre público e privado, o autor afirma que "nem tudo que é reservado às decisões de pessoas privadas deve ser subtraído à tematização pública, nem protegido da crítica”. (HABERMAS, 2003, p. 40) Ou seja, apesar da necessidade ressaltada por alguns autores de preservação da esfera privada como espaço de privacidade, o fato de certos temas, em princípio relacionados apenas a pessoas privadas, adquirirem o status de assunto de interesse geral não significaria “intromissão":

[...] a distinção correta entre as competências privadas, de um lado, e as públicas, de outro, implica o conhecimento dos contextos históricos e sociais; caso contrário não seria possível realizar adequadamente os direitos dos cidadãos. Por outro lado, a delimitação entre 
um domínio de interesses privados e autônomos e uma esfera pública da 'realização do bem comum' não pode ser feita de uma vez por todas. (HABERMAS, 2003, p. 41, grifo do autor)

Em relação a esse ponto, Mansbridge $(1999,2009)$ acredita que somente uma definição ampla de política acaba por atingir a esfera privada, na medida em que problemas tidos como íntimos ou privados se configurariam como uma questão política. Tal abertura, segundo a autora, não seria capaz de erodir a esfera privada ou subjugá-la ao Estado. A medida para a definição de uma temática como problema político seria dada por meio da resposta à pergunta "por que esse assunto demanda que duas ou mais pessoas o discutam?”. A resolução, segundo Mansbridge, "deveria mostrar que alguns problemas, embora tidos como pouco relevantes ou como muito íntimos para serem discutidos publicamente, são problemas sobre os quais o coletivo, ou o público, deve deliberar”. (MANSBRIDGE, 2009, p. 216)

Embora Mansbridge demarque uma distinção entre a própria perspectiva e a de Habermas, ao argumentar que o filósofo defende que o "político" lida com objetos conectados ao Estado, consideramos que ambas estão próximas. Entendemos que a concepção política de Habermas é suficientemente abrangente para considerar as reverberações das discussões mais cotidianas, como sustenta Mansbridge. No entanto, o foco de Habermas se volta para a circulação do poder político e para o modo pelo qual as discussões na esfera pública podem exercer pressão sob a tomada de decisão política e influenciar a legitimação de temas e políticas perante a sociedade.

Acreditamos que a diferença principal entre ambas as perspectivas é que, mais do que com temas e conteúdos, Habermas estaria preocupado com as condições de comunicação e com os fluxos entre as esferas privada e pública. Nas palavras do próprio autor: "A esfera pública retira seus impulsos da assimilação privada de problemas sociais que repercutem nas biografias particulares". (HABERMAS, 2003, p. 98) O que Habermas destaca, contudo, é que, para gerar implicações no sistema político, instância detentora do poder administrativo, uma demanda ou questão precisa ter sido objeto de escrutínio público:

Somente após uma 'luta por reconhecimento', desencadeada publicamente, os interesses questionados podem ser tomados pelas 
instâncias políticas responsáveis, introduzidos nas agendas parlamentares, discutidos e, eventualmente, elaborados na forma de propostas e decisões impositivas. (HABERMAS, 2003, p. 41)

Ambos os autores, Habermas e Mansbridge, ressaltam a importância do debate público e da discussão para politizar certo tema. Entretanto, para a autora, não existiriam enfoques pré-políticos se o assunto em questão for algo a respeito do qual duas ou mais pessoas deveriam discutir; enquanto que, para Habermas (2003), somente por meio do debate público o assunto poderia ser reconhecido como político. No processo de "luta por reconhecimento", em termos habermasianos, o papel de organizações da sociedade civil ganha centralidade na medida em que esse tipo de associação contribui para gerar visibilidade em torno do tema em questão, para organização da ação e para o aprimoramento dos argumentos, que podem ser considerados efeitos de esfera pública, próprios desse tipo de associativismo. (WARREN, 2001) Assim, o fato de haver organizações sociais envolvidas na tematização pública do TID como problema social contribui para que esse assunto seja objeto de debates públicos e adquira o status de uma questão política de acordo com a visada habermasiana. Ou seja, considerando essa perspectiva, o processo de debate público estimulado por grupos de $a d v o c a-$ $c y$ atuou para transformar o TID de um tema considerado privado em um assunto público e, portanto, concernente a uma coletividade. (CAL, 2007)

Todavia, é essencial para nossa pesquisa entender, a partir de Mansbridge (1999, 2009), que atos de resistência e de questionamento a respeito de assuntos considerados, em princípio, privados podem ser "políticos", como, por exemplo, quando a adolescente trabalhadora doméstica diz "não" à patroa que exige a realização de serviços abusivos, ou ainda quando não aceita o controle, por parte da patroa, dos alimentos que consome e sai daquela casa de família. Entretanto, a compreensão, seguindo Habermas (2003), de que um assunto adquire status político quando se torna objeto de discussão pública - o que ocorre, sobretudo, quando os impulsos originados na sociedade são canalizados e organizados por meio da ação dessas organizações da sociedade civil - traz desafios para pensarmos o TID do ponto de vista das próprias envolvidas, já que, supomos, entre elas ainda é um assunto abordado do ponto de vista mais individualizado do que coletivo, apesar da existência de grupos de advocacy no enfrentamento dessa temática, como discutido nos capítulos ume dois. 
A construção de um contexto social favorável à politização de demandas também é discutida por Honneth (2003) em relação à teoria do reconhecimento. Segundo esse autor, o caráter político dessas lutas se situa na própria construção de identidades. (HONNETH, 2003; MEDONÇA, 2012) Por meio de lutas por reconhecimento desenvolvidas a partir dos âmbitos do amor (relações íntimas), do direito e da solidariedade, sujeitos transformam experiências de desrespeito em busca de valoração pessoal e social positiva com vistas à autorrealização. Segundo Mendonça (2012, p. 131), nessa perspectiva, política se refere à coletividade e ao que fortalece ou limita condições de autorrealização dos sujeitos. Isso porque "Na medida em que as identidades são percebidas como políticas, as interações cotidianas de diversas naturezas passam a merecer atenção, visto ajudarem a compreender as opressões e lutas que atravessam processos sociais”. (MENDONÇA, 2012, p. 131) Como formas de desrespeito, Honneth (2003) aponta: a) maus-tratos e violação, que ameaçam a integridade física dos sujeitos; b) privação de direitos e exclusão, que afetam a integridade social; e c) degradação e ofensa, que ameaçam a honra e a dignidade. As reações emocionais a esses desrespeitos, segundo o autor, poderiam se tornar impulsos para lutas por reconhecimento. No entanto, essas experiências nem sempre incitam lutas políticas. Para que esse processo ocorra, é preciso que haja um contexto social propício, sobretudo, com o intermédio de movimentos sociais, para que o desrespeito se converta em "fonte de motivação para ações de resistência política". (HONNETH, 2003, p. 224)

Nesse sentido, há uma relação complexa entre o TID e lutas por reconhecimento. Isso porque, apesar dos desrespeitos infligidos às meninas e às adolescentes envolvidas nessa prática perpassarem os três âmbitos do reconhecimento, como apresentamos no capítulo um e em outros momentos (MAIA; CAL, 2012, 2014), elas não demonstram vontade de ser reconhecidas como "trabalhadoras infantis domésticas", nem como "trabalhadoras domésticas". Segundo elas, reconhecer-se e ser reconhecida assim manteria o rebaixamento moral do qual querem se distanciar. Todavia, sob outra perspectiva, os marcos teóricos propostos por Honneth estimulam o entendimento acerca de como situações extremamente desrespeitosas, relacionadas ao TID, podem incentivar a percepção e consideração de injustiças e a construção de um terreno comum para o enfrentamento dessa prática. De modo complementar, as distinções que o autor faz entre o reconhecimento justificado e o reconhecimento ideológico (HONNETH, 
2007, 2012a) contribuem para esmiuçarmos como relações de poder atentes podem ser balizadas por pressupostos racionais que fazem com que, por exemplo, o TID seja considerado uma forma de vencer na vida.

Apesar das distinções, as perspectivas de Habermas, Mansbridge e Honneth contribuem para iluminar o caso do TID e apontar elementos da politização desse tema. Retornamos, então, à nossa indagação inicial: o que faz com que um assunto seja transformado em questão política?

Acerca do TID, há um aspecto importante que merece ser considerado na resposta a essa pergunta: durante mais de 10 anos, organizações de referência no Pará e outras, internacionalmente comprometidas com a causa, atuaram fortemente no combate a essa prática e o fizeram com vistas a torná-la um assunto político, que demandava, inclusive, políticas e ações governamentais para prevenção e enfrentamento. Havia, portanto, um contexto de questionamento dessa prática, construído a partir de ações sociais e também comunicacionais do Petid, por meio dos media e das campanhas discutidas no capítulo anterior. Nesse sentido, é possível afirmar que houve um esforço de politização dessa temática a partir da ação de grupos de advocacy, o que compõe o pano de fundo de nossa pesquisa.

Contudo, a discussão pública do TID como problema era desenvolvida num terreno marcado por perspectivas históricas, culturais e sociais que alimentam esse tipo de trabalho infantil, conforme discutido no primeiro capítulo, o que nos leva a indagar a respeito de camadas mais densas de politização, que envolvem os espaços tidos como privados, a tematização de violências e desrespeitos e uma noção de política fincada no cotidiano; o que inclui, sem dúvida, uma discussão profunda sobre quem são esses sujeitos, os papéis que desempenham em nossa sociedade e por que não é desencadeada uma luta política em termos habermasianos, ou seja, um processo de debate público e de ação social em torno desse assunto, a partir dos próprios envolvidos. Ou, de modo correlato, as distintas perspectivas apresentadas, principalmente por Mansbridge e Honneth, permitem-nos visualizar outras modalidades de ação política, desenvolvidas por esses sujeitos. Nesse sentido, é possível pensar em momentos do processo discursivo de politização que passariam pela aceitação, pela resistência e subversão, pela demonstração da injustiça e pela construção de luta política a partir dos próprios sujeitos envolvidos, ainda que imersos em desigualdades sociais e em relações de poder que, em geral, limitam suas condições de manifestação. 


\section{DESIGUALDADES E RELAÇÕES DE PODER}

Desigualdades não são falhas ocasionais da vida em comunidade a serem tratadas pontualmente. Elas tampouco devem ser camufladas em nome de uma igualdade política formalmente assegurada. Desigualdades precisam ser colocadas no cerne da teoria democrática, na medida em que cerceiam a possibilidade de autogoverno e o florescimento das capacidades humanas. (MENDONÇA, 2012, p. 133)

Ao analisar a relação entre teoria do reconhecimento e democracia, Mendonça (2012) afirma que é necessário chamar atenção para as desigualdades que permeiam o cotidiano dos sujeitos e dificultam as possibilidades de autorrealização. De acordo com a teoria do reconhecimento desenvolvida por Honneth, desigualdades são consideradas desrespeitos de diferentes naturezas: (1) desrespeito em relação à integridade corporal, como maus-tratos e violação, o que gera perda de autoconfiança; (2) desrespeito como privação de direitos e exclusão, o que afeta o autorrespeito; (3) desrespeito como degradação e ofensa, ou seja, referência negativa ao valor de indivíduos (e grupos), o que resulta na perda de autoestima. (HONNETH, 2003; MENDONÇA, 2012)

Dessa forma, "o desrespeito é opressivo porque cria hierarquias depreciativas. Ele situa os sujeitos diferentemente na vida social, concedendo oportunidades a uns e negando-as a outros”. (MENDONÇA, 2012, p. 134) Assim, o autor, baseando-se na teoria de Honneth (2003), conclui que é preciso enfrentar as desigualdades que subtraem dos sujeitos o direito de serem estimados, ao mesmo tempo em que o foco do reconhecimento nas interações sociais, na intersubjetividade, portanto, dá a ver um caminho para a superação dessas desigualdades, já que "se as assimetrias e estruturas sociais são reproduzidas nas interações humanas, elas também podem ser contestadas ao longo de tais interações”. (MENDONÇA, 2012, p. 142)

Sobre essa questão, Biroli (2013), ao analisar a relação entre ressignificação da experiência a partir da tensão entre autonomia e opressão em relação às mulheres, afirma que desigualdades, especialmente as resultantes de padrões de opressão, limitam a autonomia dos sujeitos, porém não os definem. Desse modo, 
[...] defini-los como resultantes dela [opressão] significaria perder de vista, analítica e politicamente, não apenas questões relativas à subjetividade ou à vivência individual das estruturas sociais, mas fissuras e ruídos na dinâmica de reprodução da opressão e das desigualdades. (BIROLI, 2013, p. 12)

A posição de Biroli, que considera implicações estruturais, mas mantém em aberto possibilidades de brechas e "fissuras" na reprodução das desigualdades, é um contraponto em relação à perspectiva de Souza (2009). Acerca da realidade brasileira, Souza (2009) defende que haveria "consensos inarticulados" que atuariam na reprodução das diferenças sociais e funcionariam como ligações invisíveis que orientam nosso comportamento e que dizem dos papéis e das possibilidades de cada indivíduo. A partir dessa ideia, Souza (2009) argumenta que as causas da desigualdade social no Brasil, normalmente questionadas apenas pelo viés econômico, são difíceis de serem observadas a "olho nu". Uma das razões apontadas pelo autor é que a noção de justiça social estaria vinculada à meritocracia, o que nos faria considerar privilégios como sendo justos e legítimos.

De acordo com esse autor, existe uma crença generalizada na igualdade de oportunidades, de tal sorte que os bens ou a situação adquirida seriam resultados do mérito e do esforço de cada um. Por consequência, o modo naturalizado pelo qual a desigualdade é percebida no país acabaria por produzir, de um lado, sujeitos que gozam de capitais econômicos e/ou culturais e, de outro, "indivíduos sem nenhum valor", abandonados social e politicamente, que constituiriam a "ralé". Nesse grupo, estariam incluídas as trabalhadoras domésticas.

Souza (2009) defende a tese de que a constituição e a reprodução de uma classe social não dizem respeito apenas a aspectos econômicos, mas também, sobretudo, a uma herança afetiva familiar e a "valores imateriais" (aquilo que aprendemos no dia a dia com pais e/ou responsáveis e também no cotidiano de instituições como a escola). Argumenta, ainda, que há uma dimensão afetiva na cultura de classe, e que o mérito "supostamente individual" é fruto de pré-condições sociais. Assim, a "ralé" seria uma classe de despossuídos que aprenderam tacitamente que seu lugar e suas possibilidades eram distintos de sujeitos de outras classes. Existiria, então, um "consenso inarticulado", segundo o qual seria normal a divisão da sociedade "em gente e subgente": 
Ele é obviamente um consenso 'não admitido', que nenhum brasileiro de classe média jamais confessaria partilhar, e é isso que permite sua eficácia como consenso real, que produz cotidianamente a vida social e política brasileira como ela é, sem que ninguém se sinta responsabilizado por isso. (SOUZA, 2009, p. 422)

Haveria, portanto, um processo de dominação social tornado suavizado e considerado aceitável pelos próprios sujeitos em situação de subordinação, o que levaria a uma ilusão de não subjugação, na medida em que as desigualdades seriam fruto do sucesso ou fracasso de cada indivíduo. Desse modo, a dominação cotidiana seria alimentada por meios simbólicos que atuariam na legitimação das desigualdades sociais.

Uma das questões levantadas por Souza (2009) é: "por que as pessoas da ralé não reagem politicamente à humilhação diária?”. (SOUZA, 2009, p. 402) A resposta formulada pelo autor diz, no limite, que as pessoas não reagem porque não se dão conta do caráter estrutural do processo de exploração ao qual estão sujeitas, reagindo com pequenas subversões (como furtos, no caso das trabalhadoras domésticas), mas não de forma organizada e com efetividade política.

Para pensarmos o caso do TID, as análises do autor são extremamente pertinentes no que se refere à reprodução afetiva das desigualdades e à importância da dimensão simbólica em relações marcadas pelo poder. No entanto, apesar de extremamente instigante, a tese de Souza não dá a devida atenção à capacidade de agência e de percepção dos sujeitos sobre a própria condição.

Admitimos, acompanhando as proposições de Biroli (2012), que há constrangimentos sistemáticos que repercutem de forma desigual e diferenciada na forma como os sujeitos se posicionam no mundo. É o que a autora chama de "agência diferenciadamente imperfeita". De acordo com Biroli:

Essa imperfeição é o modo mesmo de expressão da agência individual, consideradas a socialização, o caráter social e intersubjetivo dos valores que são mais caros aos indivíduos e as relações de poder que atravessam, ainda que diversamente, os contextos e que as preferências individuais se definem e a agência toma forma. (BIROLLI, 2012, p. 15) 
Portanto, consideramos a agência imperfeita como expressão regular, pois os sujeitos agem em meio a constrangimentos, porém mantemos em aberto a possibilidade de agência e de questionamento do contexto a partir do qual constroem seus posicionamentos. (BIROLI, 2012)

Outro contraponto à perspectiva de Souza é oferecido pela antropóloga Jurema Brites, cuja tese de doutorado consiste na realização de uma etnografia com patroas e trabalhadoras domésticas adultas, em Vitória, no Espírito Santo. Segundo Brites (2003), para nos aprofundarmos na relação entre patroas e trabalhadoras, é preciso nos despir de visões teóricas dominantes, como a crítica ao paternalismo e ao clientelismo, que ganham contornos e justificações diferentes ao ouvirmos as próprias trabalhadoras domésticas. De outra forma, “[...] corremos o risco de, a partir de generalização, jogar por terra toda uma prática política destas mulheres em condição de subalternidade e, no seu lugar, colocarmos nossa perspectiva sobre o que seja poder, democracia e participação”. (BRITES, 2003, p. 78)

É na interseção entre as perspectivas de Souza e a de Brites que buscamos desenvolver nossa investigação. Estamos interessadas em apreender como certo jogo entre relações de poder em torno do TID atua na configuração desse tema como questão política, tanto a partir do ponto de vista das próprias envolvidas, no caso meninas e mulheres ex-trabalhadoras infantis domésticas, quanto no âmbito de visibilidade ampliada dos media. Dessa forma, é necessário tanto reconhecer a existência e atuação dessas relações de poder como mecanismos de dominação e reprodução de condições de subalternidade, quanto perceber as possibilidades de agência e de questionamento do contexto que também compõem a teia de relações na qual se inscrevem esses sujeitos.

Como ponto de partida, consideramos fundamental recorrer a algumas das principais noções de poder, pensando, principalmente, nas implicações entre dominação, resistência e solidariedade. Em seguida, em outro passo da investigação (detalhado nos capítulos quatroe cinco), analisaremos como os media trataram dessa temática nas matérias sobre o TID. Nosso objetivo é o de explorar determinadas configurações discursivas dessas relações de poder na arena pública e, também, examinar como meninas e mulheres ex-trabalhadoras infantis domésticas articulam e constroem sentido sobre (e a partir das) relações de poder em torno do TID. 


\section{QUE PODER?}

Quase todos os textos que tratam sobre o conceito de poder começam pela constatação da dificuldade de defini-lo, ou mesmo de encontrar uma essência, um núcleo central que oriente as diferentes visadas sobre o conceito. Não há como fugir dessa ressalva. Trata-se de um dos conceitos mais controversos e difíceis de operacionalizar. (PERISSINOTTO, 2008; NOBRE et al., 2008)

Diversos autores construíram tentativas de sistematização e organização das diferentes visões teóricas a respeito desse tema. (NOBRE et al., 2008; PERISSINOTO, 2008; LUKES, 1980, 2005; HAUGAARD, 2012; ALLEN, 2000, 1998 , 2013) Uma referência central nesse campo é Steven Lukes, que defende a ideia de que "poder" seria um conceito essencialmente contestado (essentially contested concept). Isso significa, por um lado, que há uma diversidade de concepções de poder e que existe uma grande dificuldade de estabelecer o que seria o cerne do conceito. (LUKES, 1980, 2005) Por outro, pode indicar exatamente a riqueza do conceito, ao dar ensejo a abordagens variadas de múltiplos fenômenos, apesar de implicar grandes desafios para operacionalização. (HAUGAARD, 2010)

De acordo com Ricardo Silva (2011), a expressão essentially contested concept refere-se a "conceitos arredios a definições unívocas” (SILVA. R, 2011, p. 03), o que significa dizer que há uma disputa entre correntes teóricas a respeito dos critérios para utilização desses conceitos. Dentre essas perspectivas contrastantes, as mais frequentes na literatura sobre o tema em tela é a tensão entre o poder como dominação (power over) e o poder como empoderamento (power to). (HAUGAARD, 2012; ALLEN, 1998)

Lukes apresenta uma explicação mais radical a respeito do poder como conceito essencialmente contestado, de tal forma que nossas próprias concepções de poder seriam moldadas por relações de poder. (ALLEN, 2013) De acordo com o autor:

[...] como pensamos em poder pode servir para reproduzir ou reforçar relações e estruturas de poder ou, alternativamente, pode desafiá-las ou subvertê-las [...] Na medida em que isto é assim, questões conceituais e metodológicas são inescapavelmente políticas e, assim, o que significa 'poder' é 'essencialmente contestado'. (LUKES, 2005 apud ALLEN, 2013, p. 4, tradução nossa). 
Ou seja, o modo como se pensa sobre poder também é atravessado por relações de poder, e diz do consentimento a elas ou do questionamento a elas infligido. Para Allen, esse tipo de afirmação sustenta a ideia trabalhada por algumas autoras feministas de que a concepção de poder como power over seria produto da dominação masculina. (ALLEN, 2013)

Em vez de fazer um longo percurso histórico e teórico na tentativa de dar conta das distintas acepções de poder, focaremos nosso esforço na discussão do poder como power over e power to. Ao final, recorremos a uma terceira concepção, que seria a de power with. Para tanto, utilizaremos como ponto de partida a sistematização feita por Allen (1998, 2000), que trabalha essas três concepções de poder a partir das perspectivas feministas. Essas concepções nos permitirão pensar sobre os conceitos de dominação, resistência, empoderamento e solidariedade. Consideramos essa escolha pertinente não apenas porque nos oferece uma possibilidade de organização da literatura a respeito desse conceito, mas porque a discussão sobre poder a partir das visadas feministas atribui um lugar destacado à família, o que é central para nosso estudo acerca do TID. Além disso, essa opção teórica e metodológica foi motivada, essencialmente, pela nossa interação com os contextos de fala e de tomada de palavra das meninas e mulheres envolvidas no TID e a percepção de que esse referencial permitiria um olhar nuançado sobre as relações de poder no TID e sobre a politização de seu enfrentamento.

\section{Power over}

Um das definições mais clássicas de poder é a de Max Weber, segundo quem "Poder significa toda probabilidade de impor a própria vontade numa relação social, mesmo contra resistências, seja qual for o fundamento dessa probabilidade”. (WEBER, 1991a, p. 33) O poder é considerado, nessa perspectiva, portanto, uma relação de imposição da vontade. (PERISSINOTO, 2008; HABERMAS, 1993; ALLEN, 2013)

Habermas (1993) interpreta essa conceituação de Weber como a capacidade de dispor de meios para influenciar a vontade de outro sujeito. De acordo com Perissinotto (2008), o poder, para que possa ocorrer, precisa de um fundamento ou de recursos que, no entanto, são apenas "bases prováveis": "quem controla um dado recurso tem a probabilidade de exercer poder sobre outras pessoas caso 
queira”. (PERISSINOTO, 2008, p. 32, grifo do autor) Desse modo, o poder de um determinado agente não deve ser medido a partir da quantidade de recursos de que dispõe, mas do modo pelo qual são utilizados em determinada relação social. (WEBER, 1991a; PERISSINOTO, 2008; CLEGG, 1989)

Perissinoto (2008), embasado em Russell, afirma que a ideia de "imposição da própria vontade numa relação social”, refere-se a efeitos pretendidos de tal modo que seja possível estabelecer uma relação causal entre o efeito gerado a partir da relação de poder e a intenção do agente em produzi-lo. Portanto, em uma relação de poder (como power over), a imposição da vontade não necessitaria do uso da força ou da violência de forma explícita, e sim da mobilização do medo e do receio de perder algo que é valorizado. Segundo Perissinoto, “o fato de que o poder tenha uma dimensão essencialmente coativa não quer dizer que se baseie apenas no uso da violência. A violência física é apenas uma dentre várias outras formas de sanção, mas nem de longe a mais corriqueira”. (PERISSINOTO, 2008, p. 33)

De modo geral, podemos entender power over como o exercício de formas de dominação ou controle de outrem com vistas a obter um resultado desejado. (HENDRIKS, 2009) De acordo com Lukes (1980), a partir desse entendimento, o poder seria uma soma de resultado zero, já que, enquanto um ganha, o outro perde.

Lukes analisa a discussão e a literatura sobre esse tipo de poder a partir de três dimensões: unidimensional, bidimensional e tridimensional. (LUKES, 1980; HAUGAARD, 2012; HENDRIKS, 2009) A primeira e a segunda dimensão são fortemente influenciadas pelas proposições weberianas. (LUKES, 1980; PERISSINOTO, 2008) A visão unidimensional trata o poder como um conflito observável de tal forma que " $A$ tem poder sobre $B$ na medida em que pode fazer com $B$ faça algo que de outro modo não faria”. (DAHL, 1957, p. 202-203, grifo do autor, tradução nossa) De acordo com Dahl (1957), um dos principais teóricos dessa abordagem, a base do poder (potencialmente) consiste nos recursos que um ator pode explorar de modo a influenciar o comportamento de outro. Por recursos, este autor compreende oportunidades, atos e objetos, dentre outros.

A respeito das relações de poder, Dahl (1957) afirma que elas apresentam três condições necessárias: (a) os tempos de ação de A e B precisam ser diferentes. Portanto, para que seja uma relação de poder, é preciso que a ação (ou resposta) de B seja posterior à ação de A; (b) é essencial haver "conexão" entre A e B, nas palavras do autor: "não existe 'ação à distância” (DAHL, 1957, p. 204, tradução 
nossa) e (c) deve ser possível poder mensurar se a quantidade de poder de A sobre $\mathrm{B}$ gerou algum resultado.

O conflito, nessa perspectiva, refere-se a disputas entre preferências explicitadas em ações e observáveis a partir da análise do comportamento das pessoas. (LUKES, 1980) Para comprovar que uma determinada relação é de poder (ou de dominação) seria necessário, então, examinar as decisões tomadas. Nesse sentido, "decidir é a capacidade de definir o curso dos eventos de acordo com os interesses de quem decide e em detrimento dos interesses de quem se submete”. (PERISSINOTO, 2008, p. 35) A base metodológica desse modelo baseado "no conflito observável entre preferências antagônicas" traz em si as evidências necessárias para análise do poder entendido de modo unidirecional. (LUKES, 1980; PERISSINOTO, 2008)

A visão bidimensional do poder, como mencionamos, é também tributária da concepção weberiana, porém critica as proposições da visão unidimensional por considerá-las restritivas e extremamente comportamentais. (ALLEN, 2013; LUKES, 1980; PERISSINOTO, 2008) Bachrach e Baratz são as principais referências dessa segunda dimensão do power over. Eles buscam salientar que o poder não pode significar apenas a capacidade de tomar decisões. "Ao contrário, defendem que a face mais importante do poder se encontra no processo seletivo por meio do qual determinados temas são retirados da agenda política”. (PERISSINOTO, 2008, p. 38) Para Hendriks (2009), trata-se de uma forma indireta de power over, a partir da qual A manipula as regras do jogo de modo a fazer com que B haja do modo como A gostaria.

Tal processo ocorreria por meio da "mobilização de predisposições" (mobilization of bias), que se referem aos valores dominantes, aos mitos, aos procedimentos políticos estabelecidos e às regras do jogo. Assim, para analisar as relações de poder, seria necessário investigar quais pessoas (ou grupos) ganhariam com a tendência predominante ou seriam prejudicados por ela. (BACHRACH; BARATZ, 1962, p. 952) O passo seguinte consistiria da observação da dinâmica da não tomada de decisão, o que para Bachrach e Baratz significa "examinar a medida que e a maneira pela qual o status quo, orientado por pessoas e grupos, influencia os valores da comunidade e as instituições políticas que tendem a limitar o escopo da tomada de decisões para assuntos 'seguros”. (BACHRACH; BARATZ, 1962, p. 952, tradução nossa, grifo nosso) Seguros, seriam assuntos cuja discussão não ameaçasse os interesses dos grupos dominantes. (PERISSINOTO, 2008) 
Apesar da crítica às proposições de Dahl, Lukes (1980) analisa que Bachrach e Baratz se aproximam bastante do primeiro ao enfatizarem o conflito real, observável, aberto ou encoberto, como única forma metodologicamente analisável. Para Perissinoto (2008), os últimos autores têm o mérito de incluírem na discussão política a ideia de que as formas pelas quais consensos são construídos trazem implicações ao conceito de poder. No entanto, teriam falhado ao trabalhar essa temática do ponto de vista apenas da formulação de políticas públicas. De acordo com Perissinoto,

\section{[...] uma das formas de salvaguardar a proposição de que pode haver poder em relações de consenso é aceitar que as evidências a serem apresentadas em seu favor são de outra natureza e o seu campo de atuação bem mais amplo do que a produção de políticas públicas. (PERISSINOTO, 2008, p. 41)}

É justamente nesse terreno, em relação ao poder que permeia a construção de consensos, que Lukes situa a visão tridimensional de poder. Segundo esse autor, ordens sociais existentes sustentam seu poder por meio de práticas institucionalizadas e "verdades" culturalmente aceitas. Lukes (1980) entende "poder" como a capacidade de afetar significativamente o outro, mesmo de forma subjacente e não explícita para o sujeito concernido. Por essa razão, nem precisaria haver um conflito real entre as partes para que as relações de poder fossem percebidas, mas sim um conflito latente (constituído por uma contradição entre os interesses dos que detêm o poder e os "verdadeiros interesses" daqueles por eles afetados). Portanto, as relações de exploração seriam normalmente subjacentes às práticas e aos posicionamentos dos atores sociais.

De modo complementar, Hendriks (2009) afirma que a terceira dimensão de poder pode ocorrer de duas formas: (1) quando A usa símbolos para influenciar o modo pela qual B percebe as desigualdades em torno de si e também seus desejos e demandase ainda (2) quando A contribui para moldar o modo pelo qual B visualiza possibilidades de mudança, fazendo com que B considere inapropriado e contraproducente questionar o poder de A. Todavia, Lukes (2005) ressalta que poder é um conceito disposicional e que, portanto, diz respeito a uma capacidade que pode ou não ser exercida. Nas palavras de Lukes: 
Minha visão foi e é a de que nós precisamos pensar sobre poder de forma mais ampla ao invés de estreita - em três dimensões ao invés de uma ou duas - e que precisamos atentar para aqueles aspectos do poder que são menos acessíveis à observação: que, de fato, o poder é mais efetivo quando menos observável. (LUKES, 2005, p. 1, tradução nossa)

Além de sérios desafios metodológicos que esse modelo pressupõe (como examinar essas formas menos visíveis de poder?), ${ }^{1}$ a teoria de Lukes a respeito do conceito recebeu inúmeras críticas. Trinta anos depois do seu influente livro Poder: uma visão radical, o autor lançou uma segunda edição na qual reproduz a primeira e acrescenta dois capítulos com objetivo de responder a objeções recebidas e, ao final, reafirmar seu posicionamento.

Um dos pontos discutidos é a ideia do conflito latente. Alguns críticos identificaram similaridade com um problema antigo, de origem marxista: a falsa consciência. Entretanto, Lukes (2005) procura esclarecer que se trata de um conceito distinto. Isso porque ilusões internalizadas podem ser, de acordo com o autor, compatíveis com posicionamentos racionais que justificariam a vida daquela forma. Assim,

\begin{abstract}
A terceira dimensão do poder é sempre focada em determinados domínios da experiência e nunca é, exceto em distopias ficcionais, mais do que parcialmente eficaz. Seria simplista supor que a complacência 'disposta' e 'relutante' à dominação são mutuamente excludentes: uma pessoa pode consentir ao poder e se ressentir do modo do seu exercício. (LUKES, 2005, p. 150, tradução nossa).
\end{abstract}

Em relação à ideia de processos latentes de poder e dominação, Perissinoto (2008) afirma que, apesar de diferenças teóricas e metodológicas, Lukes e Bourdieu compartilham a percepção de que as relações de poder são calcadas

1 Relevante destacar que tanto na primeira edição de Poder: uma visão radical quanto na segunda, Lukes busca convencer ao leitor de modos pelos quais seria possível responder a essa questão a partir de um balanço entre o que seriam os reais de interesses de pessoas ou grupos e o que é resultado de relações latentes de poder. Como observa Perissinoto, "a abordagem de Lukes só nos permite analisar relações de poder que já se desintegraram em função do advento de crises ou oportunidades de mobilidade social. As relações presentes são, para essa perspectiva, uma incógnita". (PERISSINOTO, 2008, p. 44) 
em certa adesão dos dominados aos valores dominantes, de modo que a dominação seja percebida como um acordo tácito. Perspectiva essa que alimenta as formulações sobre a naturalização da desigualdade de Souza (2009).

Bourdieu defende a ideia de que as classes dominantes seriam detentoras de um capital simbólico espraiado em práticas e instituições sociais, o que permite exercer o poder. (BOURDIEU, 1989; CAPPELLE; MELO; BRITO, 2005; VASCONCELLOS, 2002) Esse tipo de capital é resultante do poder simbólico, definido pelo autor como:

\section{[...] poder quase mágico que permite obter o equivalente daquilo que é obtido pela força (física e econômica) [...] Isto significa que o poder simbólico não reside nos 'sistemas simbólicos' em forma de uma 'il- locutionary force' mas se define numa relação determinada - e por meio desta - entre os que exercem o poder e os que lhe estão sujeitos. (BOURDIEU, 1989, p. 14)}

Desse modo, "trata-se de um poder que não produz ameaças, mas sim o convencimento e a submissão simbólica ao estado atual das coisas”. (PERISSINOTO, 2008, p. 15) O conceito de habitus desenvolvido por Bourdieu articula-se com essa perspectiva sobre poder na medida em que se trata de um sistema de disposições construídas socialmente e traduzidas em estilos de vida, julgamentos políticos e morais. (BOURDIEU, 1998; VASCONCELLOS, 2002; LUKES, 2005) Segundo Bourdieu, habitus refere-se a "estruturas estruturadas e estruturantes [que] constituem o princípio gerador e unificador do conjunto de práticas e das ideologias características de um grupo de agentes”. (BOURDIEU, 1998, p. 191)

Para Lamarão (2008), a perspectiva de Bourdieu é importante para sustentar o entendimento acerca de como a subalternidade e o estigma podem se constituir como produto de uma história incorporada ao habitus. E, desse modo, para alimentar um tipo de violência quase invisível que o autor nomeia como violência simbólica. (LUKES, 2005)

Boa parte das perspectivas que orientam, de acordo com Lukes (1980; 2005), essa terceira dimensão do poder usam como ponto de partida a ideia de que haveria um consenso que alimenta relações de poder. No entanto, Foucault (1995) alerta que o poder não é da ordem do consentimento. O autor reconhece que a relação de poder pode ser resultado de um consenso (anterior ou permanente), 
porém a sua natureza não é a manifestação desse consenso. Isso porque poder, para ele, refere-se à ação. Não sobre quem se exerce poder, porém sobre sua própria ação ${ }^{2}$. Nesse sentido, segundo Foucault (1995), poder é distinto de violência na medida em que uma relação de poder pressupõe uma abertura, um terreno para a resistência:

Uma relação de poder, ao contrário [de uma relação de violência], se articula sobre dois elementos que lhe são indispensáveis por ser exatamente uma relação de poder: que o 'o outro' (aquele sobre o qual ela se exerce) seja inteiramente reconhecido e mantido até o fim como sujeito da ação; e que se abra, diante da relação de poder, todo um campo de respostas, reações, efeitos, invenções possíveis. (FOUCAULT, 1995, p. 244)

Portanto, a analítica do poder ${ }^{3}$ de Foucault enfatiza o aspecto produtor e produtivo do poder. (MAIA, A., 1995; HAUGAARD, 2012) Com base nesse autor, Haugaard (2012) questiona a ideia de que relações de poder têm sempre um resultado de soma zero ${ }^{4}$. Haugaard (2012) chega à constatação de que, se as relações de poder são sustentadas pela internalização de constrangimentos, elas não podem ter como resultado sempre soma zero: "Se todos os exercícios de power over, de A sobre B, forem de soma zero, em que B nunca realizou os seus interesses, a complacência disposta seria improvável - você pode enganar as pessoas por algum tempo, mas não todo o tempo”. (HAUGGARD, 2012, p. 25, tradução nossa)

2 "Uma ação sobre a ação, sobre ações eventuais, ou atuais, futuras ou presentes". (FOUCAULT, 1995, p. 244)

3 Foucault não construiu uma teoria sobre poder, ao invés disso, analisa, a partir do estudo de diferentes empirias, relações de poder. Por essa razão, o próprio autor prefere utilizar o termo "analítica" a "teoria". A discussão sobre poder em Foucault encontra-se espraiada por toda sua vasta obra. Ao longo do tempo, houve mudanças na forma como o autor conceituou poder. (MAIA, A. 1995), (LUKES, 2005) Neste trabalho, utilizamos como referência o texto mais recente e mais organizado a respeito desse assunto. (MAIA, A., 1995) Trata-se de "O sujeito e o Poder", publicado em inglês em 1982 e, em português, em 1995.

4 Ideia rotulada por Parsons a partir da teoria dos jogos, de acordo com a qual "o poder era assim definido nos termos de objetivos mutuamente excludentes, de modo que uma parte seria detentora de poder na medida em que realizaria seus próprios desejos à custa daqueles que constituíam a outra parte. [...] no mesmo grau que uma parte vence, a outra necessariamente perde". (GIDDENS, 1998, p. 242) 
Na versão original em inglês do texto O sujeito e o poder, Foucault faz uma breve referência ao poder como indo além de uma relação de soma zero. Na versão em português, essa referência foi suprimida e, por isso, optamos pela tradução livre desse trecho feita por Maia (1995):

Só podemos falar de estruturas ou de mecanismo de poder na medida em que supomos que certas pessoas exercem poder sobre outras. O termo 'poder' designa relacionamentos entre parceiros (e com isto não menciono um jogo de soma zero, mas simplesmente, e por ora me referindo em termos mais gerais, a um conjunto de ações que induzem a outras ações, seguindo-se uma às outras). (FOUCAULT, 1982 apud MAIA, A., 1995, p. 89)

Há, portanto, elementos racionais que justificariam e estariam na base de sustentação de relações de poder, entendidas como power over, de tal forma que "o poder como dominação seria parasitário em relação ao poder como emancipação”. (HAUGAARD, 2012, p. 26, tradução nossa) É, a partir dessa perspectiva, por exemplo, que podemos entender o modo pelo qual o TID é apresentado por trabalhadoras como um meio para obter relativa autonomia em relação à situação de suas próprias famílias e ter acesso a bens culturais diferenciados, como viagens.

De acordo com Allen (1998), "power over” e "dominação” não podem ser entendidos como sinônimos, apesar desse último consistir num tipo importante de aplicação do primeiro. Allen define power over como "a habilidade de um ator ou grupo de atores em constranger as escolhas disponíveis para outro ator ou grupos de atores de forma não trivial”. (ALLEN, 1998, p. 33, tradução nossa) A autora ressalta que, para as feministas, é importante retirar as palavras "estratégia" ou "intenção" da concepção de poder porque boa parte do poder que interessa para a teoria feminista (e também para a nossa pesquisa) “é mantida ou exercida 'rotineiramente ou de formas não consideradas [poder]' por pessoas que não necessariamente têm intenção deliberada de fazê-lo”. (ALLEN, 1998, p. 33, tradução nossa)

Dominação, então, para essa autora, consiste num tipo de power over que restringe as opções de escolha do ator (ou de um grupo de atores) de modo não trivial e de uma forma que seja desvantajosa para ele (ou eles). Para esclarecer o 
conceito, ela utiliza como exemplo o caso de uma técnica de basquete que exerce um tipo de power over sobre as jogadoras, mas que é distinto de dominação na medida em que ele não é (pelo menos idealmente) aplicado de forma desvantajosa a elas. Acreditamos que essa definição de dominação, apesar de operacional, deixa em aberto como definir o que seria vantajoso ou não.

Ainda sem resposta suficiente para essa questão, consideramos que um retorno aos tipos puros de dominação weberianos pode contribuir para aprimorar os contornos desse conceito. De acordo com Weber (1991b), dominação referese à probabilidade de encontrar obediência. Para o autor, os tipos puros seriam três: (1) dominação legal, que se apoia internamente em bases jurídicas; (2) dominação tradicional, baseada na crença e nos costumes, cujo exemplo mais importante é a dominação patriarcal; (3) dominação carismática, baseada na devoção afetiva.

A dominação encontrada no TID estaria, como já apresentado no primeiro capítulo, relacionada principalmente à tradicional, por ser sustentada por aspectos culturais e sociais, sobre, por exemplo, o lugar que as meninas domésticas devem ocupar nas famílias para as quais trabalham e por ter o lar como espaço de atuação.

No entanto, essa seria apenas uma parte da história sobre poder. A respeito da teoria feminista acerca do assunto, Allen $(1998,2013)$ considera que tanto as "teóricas da dominação" - tendem a enfatizar demais a vitimização das mulheres e a não considerarem formas de poder que elas mobilizam -, quanto as "teóricas do empoderamento" - advogam pela consideração do poder das mulheres a partir valorização de atividades e capacidades que seriam peculiares a esse grupo social (como cuidado, maternidade) - desenvolvem abordagens incompletas por não considerarem "as complexas formas pelas quais mulheres podem ser tanto dominadas quanto empoderadas ao mesmo tempo e no contexto de uma mesma prática, instituição ou norma”. (ALLEN, 1998, p. 22, tradução nossa) Nesse sentido, buscamos analisar, no contexto do TID, essa complexa articulação entre dominação e empoderamento de meninas e mulheres.

Para entender melhor o fenômeno do poder no feminismo, Allen (1998) propõe uma abordagem integrada que considere a dominação masculina, o empoderamento feminino e a construção de solidariedade e coalisão entre as mulheres, o que não pode ser entendido se poder for considerado apenas power over. A 
nosso ver, relações de poder desse tipo estão ligadas ao processo de aceitação e de individualização de um problema com potencial político, como é o caso do TID.

\section{Power to}

Além de power over, outra instância do poder apontada por alguns autores é power to. (ALLEN, 1998, 2013; CSASZAR, 2004; HAUGAARD, 2010) Esse tipo de poder estaria ligado tanto à capacidade de ação quanto a formas de empoderamento. Allen o define como "a habilidade de um ator individual de atingir um objetivo ou uma série de objetivos”. (ALLEN, 1998, p. 34, tradução nossa)

Assim, o poder, entendido de maneira ampla, teria uma dupla capacidade, conforme apontado por Chazel (1995): tanto a de realizar e manter quanto a de desfazer modos de dominação. Por essa razão, há bastante crítica em relação à necessidade e aos ganhos de se manter a distinção entre power over e power to. No entanto, consideramos que estabelecer distinções é fundamental para permitir uma análise nuançada da complexidade das relações de poder. Com essa finalidade, recuperamos elementos da definição feminista de power to que são importantes para a discussão que propomos neste trabalho. Na conceituação desenvolvida pelas "teóricas do empoderamento", power to faz referência à construção e perseguição de projetos de vida, à valorização a formas de transformação e de empoderar a si e aos outros. (ALLEN, 1998, 2013) Empoderamento e resistência são palavras-chave nesse contexto.

Por empoderamento entendemos o desenvolvimento da própria capacidade de alcançar certos objetivos, apesar de situações de subordinação, ou, pensando no caso feminista, apesar da dominação masculina. (ALLEN, 1998, 2013) Na tentativa de explicar melhor o termo, recorremos de modo complementar à discussão contemporânea a respeito do assunto, no que concerne ao enfrentamento da pobreza. Nesse sentido, Romano (2002) ressalta que o termo se refere a um processo de conquista particular:

O empoderamento não é algo que pode ser feito a alguém por uma outra pessoa. Os agentes de mudança externos podem ser necessários como catalisadores iniciais, mas o impulso do processo se explica pela extensão e a rapidez com que as pessoas e suas organizações se mudam a si mesmas. [...] O que as políticas e as ações governamentais 
podem fazer é criar um ambiente favorável ou, opostamente, colocar barreiras ao processo de empoderamento. (ROMANO, 2002, p. 14)

A formulação de Romano (2002) sobre empoderamento, ao mesmo tempo em que traz um desafio ànossa perspectiva, já que o considera uma ação em que os sujeitos mudam a si mesmos, contribui para pensarmos num contexto em que o TID é questionado de modo externo às afetadas por meio de organizações de advocacy: como os sujeitos diretamente envolvidos no TID constroem sentido acerca desse processo, e o que tais sentidos podem revelar sobre relações de dominação e empoderamento que atravessam e sustentam essas atividades?

A outra face do power to é a resistência. Como Foucault (1995) afirma, onde há poder, há resistência. Segundo Allen (1998), essa é uma forma particular de aplicação do power to, em posição semelhante à da dominação em relação ao power over. Resistência seria, então, a capacidade de um sujeito alcançar um ou mais objetivos com a finalidade de colocar em xeque situações de dominação e/ ou, poderíamos acrescentar ainda, escapar delas em buscar de uma vida melhor. (ALLEN, 1998)

Olhar para a resistência significa reconhecer lutas que não se travam na forma de uma confrontação coletiva. (SCOTT, 2011) Trata-se de considerar formas cotidianas de resistência, subversão e enfretamento ao poder como dominação. As "armas", nesse caso seriam, como aponta Scott (2011) ao se referir à luta dos camponeses frente aos senhores aos quais eram subordinados: sabotagem, relutância, pequenos furtos, dissimulação, difamação, simulação de ignorância, entre outras. De acordo com esse autor, "a resistência cotidiana é informal, muitas vezes dissimulada, e em grande medida preocupada com ganhos de facto imediatos”. (SCOTT, 2011, p. 223, grifo do autor)

Considerar, portanto, poder como power to contribuirá para analisarmos essas outras práticas políticas de meninas e mulheres envolvidas com o TID tanto relacionadas à resistência a situações opressivas no TID, a exemplo de quando a menina doméstica enfrenta a imposição do pai, mas se recusa a voltar para a casa de família em que vinha sendo assediada pelo patrão, ou ainda resistências frente ao TID quando há a tentativa de superação daquele modo de vida em busca de outro considerado mais digno por elas. 


\section{Power with}

A terceira distinção analítica que faremos em relação ao conceito de poder é power with, inspirada na perspectiva de Hannah Arendt, segundo a qual o poder se refereà construção de uma vontade comum. (ARENDT, 1994; HABERMAS, 1993) De acordo com autora, "poder corresponde à habilidade humana não apenas para agir, mas para agir em concerto”. (ARENDT, 1994, p. 36) Essa instância do poder, portanto, contribui para pensarmos na construção de laços e identificações que estão na base de processos de ação coletiva. Como afirma Perissionoto (2004) sobre o pensamento de Arendt, o poder emerge quando um grupo é formado e some quando ele é desfeito. Desse modo, power with pode ser definido como uma "habilidade coletiva de agir em conjunto para atingir um objetivo ou uma série de objetivos comuns ou partilhados”. (ALLEN, 1998, p. 35)

Pensar relações de poder como power with diz respeito, então, à construção de solidariedade e de coalisão entre sujeitos. Como explicam Guinier e Torres, "Este poder é gerador, envolve compartilhar algo ou se tornar algo, não apenas dar, demandar ou consumir. Ele se expande no seu exercício. Ele encontra uma maneira de chamar as pessoas a se conectar com algo maior do que elas mesmas”. (GUINIER; TORRES, 2002 apud HENDRIKS, 2009, p. 178, tradução nossa) Um processo pelo qual essa conexão pode ocorrer é por meio das trocas argumentativas, quando posicionamentos e pretensões de validade são testados (HABERMAS, 1984), e também quando problemas que atingem determinados sujeitos podem ser coletivizados a ponto de promoverem o engajamento em torno das melhores formas possíveis de resolvê-los.

Desse modo, a solidariedade se torna, assim, uma maneira central de aplicação desse tipo de poder, ainda que não exclusiva, assim como são a dominação e a resistência para as outras modalidades de poder, respectivamente, power over e power to. (ALLEN, 1998, 2000) Entendemos solidariedade relacionada ao power with como "habilidade de uma coletividade para agir em conjunto por uma finalidade comum ou compartilhada de enfrentar um sistema de dominação”. (ALLEN, 1998, p. 36)

De acordo com Melucci (2001), solidariedade se refere à capacidade dos atores de se reconhecerem e serem reconhecidos como parte da mesma comunidade ou grupo. Nesse sentido, a ação coletiva não seria resultante de forças naturais, mas sim de um processo de identificação, de construção de uma iden- 
tidade coletiva. Essa identidade, segundo Melucci, "tem predominantemente o caráter de um processo que deve ser continuamente ativado para tornar possível a ação". (MELUCCI, 2001, p. 69) Por meio desse "nós”, é possível articular interesses e mobilização e dar consistência às ações coletivas. (MELUCCI, 2001) Entendemos que a formação de solidariedade é um dos passos básicos para a construção de ações coletivas, a partir dos próprios sujeitos afetados pelo TID porque permite a identificação de injustiças comuns e a construção de um terreno compartilhado de ação.

A solidariedade e a construção de uma identidade coletiva também são bases para os movimentos de luta por reconhecimento. Para que isso ocorra, segundo Honneth (2003), é necessário que a experiência de desrespeito e o sentimento de injustiça sejam considerados como algo que afeta não apenas um indivíduo, mas um grupo inteiro. Assim:

Sentimentos de lesão dessa espécie só podem tornar-se a base motivacional de resistência coletiva quando o sujeito é capaz de articulá-los num quadro de interpretação intersubjetiva que os comprova como típicos de um grupo inteiro; nesse sentido, o surgimento de movimentos sociais depende da existência de urna semântica coletiva que permite interpretar as experiências de desapontamento pessoal como algo que afeta não só o eu individual mas também um círculo de muitos outros sujeitos. (HONNETH, 2003, p. 258)

É fundamental, então, que exista uma "ponte semântica” que ligue a experiência individual de desrespeito às finalidades impessoais de um movimento social. (HONNETH, 2003) Segundo esse autor, o próprio engajamento em atuações políticas estimula que os sujeitos saiam da situação "paralisante do rebaixamento passivamente torelado", o que contribui para que se sintam valorizados por estarem lutando contra aquilo que provoca sofrimento, o que estimula uma autorrelação positiva. (HONNETH, 2003)

Além disso, para Honneth (2012b), sentir-se parte de um grupo social faz com que sujeitos a quem é negado reconhecimento possam ter acesso a um tipo compensatório de respeito,que não é equivalente a ser reconhecido como um sujeito de direitos e membro de determinada sociedade, mas é o que se goza a partir do reconhecimento dentro do grupo específico do qual se participa. De 
modo complementar, Honneth (2003) acrescenta que a solidariedade dentro de um grupo político estimula a experiência de reconhecimento e propicia a conquista um tipo de estima mútua.

Em relação ao TID, a percepção e a consideração das injustiças que essa prática provoca poderia estimular a construção de solidariedade e o entendimento de que se trata de um problema coletivo, e não individual. Nesse sentido, o próprio engajamento nesse processo poderia trazer ganhos para as meninas e mulheres afetadas, por estimular o autorrespeito e a estima social. Esse processo seria beneficiado ainda pelo contexto social já existente de luta empreendida por organizações de advocacy contra o TID, o que foi detalhado no capítulo dois. Portanto, o entendimento do poder como power with e as perspectivas de Melucci e Honneth acerca da construção de um "nós” político estimulado por relações de solidariedade a partir das quais se sedimenta um terreno compartilhado de ação permitem que compreendamos como as experiências individuais de desrespeito podem se conectar com motivações mais amplas para a luta a partir das próprias meninas e mulheres afetadas pelo TID.

Neste capítulo, discutimos o que torna um assunto uma questão política com objetivo de conceituar o que estamos tratando por "político" e apresentar alguns pontos de distinção entre as definições apresentadas. Como estamos preocupados em investigar o jogo entre distintas relações de poder que atuam na configuração do TID, realizamos, ainda, uma incursão em teorias sobre poder para destacar três nuances que nos parecem caras a este trabalho: power over; power to e power with. No centro dessas definições, estão, respectivamente, dominação, resistência e empoderamento e solidariedade, que possuem, a nosso ver, diferentes repercussões para a configuração política do TID. 